\title{
PENGARUH REAL LABORATORY DAN VIRTUAL LABORATORY TERHADAP KUALITAS PROSES PADA MATERI KESETIMBANGAN KIMIA
}

\author{
Mawadatur Rohmah ${ }^{1, *)}$, Suhadi Ibnu ${ }^{2, * *}$, dan Endang Budiasih ${ }^{3, * * *)}$ \\ ${ }^{1}$ Universitas Wahidiyah \\ ${ }^{2,3}$ Universitas Negeri Malang \\ ${ }^{*}$ E-mail: mawadaturrohmah89@gmail.com
}

\begin{abstract}
Abstrak: Kesetimbangan kimia adalah salah satu materi kimia yang dianggap memiliki beberapa konsep sulit, sehingga harus disampaikan menggunakan model pembelajaran untuk meningkatkan pemahaman konsep peserta didik, salah satunya dengan model pembelajaran Learning Cycle $5 E$ menggunakan real laboratory dan virtual laboratory. Tujuan penelitian ini adalah untuk mengetahui pengaruh penggunaan model pembelajaran Learning Cycle $5 E$ dengan real laboratory dan virtual laboratory terhadap kualitas proses pembelajaran pada materi kesetimbangan kimia. Rancangan penelitian ini menggunakan rancangan eksperimen semu dengan analisis data deskriptif. Populasi penelitian ini adalah siswa kelas XI MIA SMA Negeri 2 Malang, menggunakan convenience sampling dan diperoleh sampel penelitian siswa kelas XI MIA 4 (LC 5E dengan real laboratory) dan siswa kelas XI MIA 5 (LC 5E dengan virtual laboratory). Instrumen yang digunakan berupa instrumen perlakuan yang terdiri dari RPP dan bahan ajar, serta instrumen pengukuran yang terdiri dari lembar RTOP, lembar observasi keterlaksanaan pembelajaran, serta lembar penilaian afektif dan psikomotorik. Hasil penelitian menunjukkan bahwa kualitas proses dengan model pembelajaran LC 5E menggunakan real laboratory dan virtual laboratory terlaksana dengan baik, serta penilaian afektif dan psikomotorik peserta didik mencapai ketuntasan sebesar $100 \%$.
\end{abstract}

Kata kunci: kualitas proses, real laboratory, virtual laboratory.

\section{PENDAHULUAN}

Pergeseran pembelajaran yang lebih mengarah pada pandangan konstruktivisme, membuat guru lebih berperan sebagai fasilitator belajar dan lebih medorong pada belajar mandiri oleh peserta didik. Pendekatan yang mampu menggali gagasan awal peserta didik yang selanjutnya dapat dijadikan acuan untuk membangun pemahaman konsep yaitu pendekatan inkuiri (Kirna, 2010). Salah satu model pembelajaran yang menggunakan pendekatan inkuiri adalah learning cycle. Model pembelajaran learning cycle berkembang dari 3 fase, 4 fase, 5 fase dan lebih dari 5 fase. Dari berbagai pengembangan learning cycle tidak ada perbedaan yang mendasar pada fase - fase tersebut karena unsur unsur dasar dalam pembelajaran learning cycle tidak berubah, yaitu unsur eksplorasi, unsur penemuan atau pengenalan dan unsur penerapan konsep (Iskandar, 2011)

Dalam penelitian ini digunakan model pembelajaran learning cycle $5 E$. Hal ini dilakukan karena peneliti menganggap sintaks model pembelajaran learning cycle $5 E$ sesuai dengan karakteristik materi kesetimbangan kimia sehingga peserta didik diharapkan mampu memperoleh pengalaman dan pemahaman konsep yang utuh dan benar sesuai dengan fase - fase learning cycle 
5E. Menurut Bybee, dkk (2006:1) pengembangan model pembelajaran berdasarkan Biological Science Curriculum Study (BSCS), learning cycle 5E terdiri dari 5 fase, yaitu fase engagement, fase exploration, fase explanation, fase elaboration dan fase evaluation.

Berdasarkan teori belajar konstruktivistik Piaget, terdapat dua fungsi dasar perolehan konsep, yaitu organisasi dan adaptasi (Dahar, 2011). Fungsi organisasi dan adaptasi pada model pembelajaran LC 5E ditunjukkan pada fase exploration, dimana pada fase exploration peserta didik diharapkan mengalami ketidakseimbangan kognitif (disequilibrium) (Dasna \& Sutrisno, 2005). Ketidakseimbangan kognitif ini akan membuat peserta didik mengalami proses asimilasi dan akomodasi terhadap fenomena baru yang diberikan, sehingga peserta didik akan mencoba untuk menghubungkan fenomena baru ini dengan konsep yang telah mereka pelajari sebelumnya. Proses yang dilalui peserta didik ini akan menyebabkan modifikasi dan pengembangan struktur kognitifnya berdasarkan pengalaman yang telah dilakukan.

Dampak teori konstruktivistik Piaget terhadap pembelajaran adalah guru harus lebih menekankan pentingnya peran pengalaman bagi peserta didik atau interaksi peserta didik dengan lingkungan di sekelilingnya (Suyono \& Haryanto, 2014). Pemberian pengalaman secara langsung pada peserta didik dengan harapan peserta didik dapat bekerja memanipulasi objek, melakukan percobaan (secara ilmiah), melakukan pengamatan, mengumpulkan data, sampai pada membuat suatu kesimpulan dari percobaan yang dilakukan (Dasna \& Sutrisno, 2005). Proses modifikasi dan pengembangan struktur kognitif peserta didik dapat dilakukan melalui suatu kegiatan praktikum. Dalam kesetimbangan kimia banyak konsep penting yang harus dicari jawabannya melalui percobaan, dugaan atau hipotesis, analisis data, pembahasan dan kesimpulan (Setiawan, 2011)

Pembelajaran yang melibatkan kegiatan praktikum biasanya dilakukan di dalam laboratorium, yang dalam pembelajaran kimia dibagi menjadi dua, yaitu real laboratory (laboratorium riil) dan virtual laboratory (laboratorium virtual). Pada real laboratory banyak hambatan dan keterbatsan yang kadang sering terjadi, misalnya adanya beberapa percobaan yang dapat membahayakan keselamatan peserta didik, waktu yang dibutuhkan untuk persiapan lebih lama, sehingga peserta didik merasa penggunaan real laboratory masih kurang maksimal.

Solusi yang diberikan untuk mengatasi masalah tersebut adalah dengan mengamati animasi atau video eksperimen, yang disebut dengan virtual laboratory. Virtual laboratory merupakan suatu program aplikasi (software) yang dirancang khusus untuk kegiatan eksperimen dan dioperasikan dengan komputer, berisi animasi - animasi peralatan, bahan dan proses yang terjadi menyerupai kejadian sesungguhnya, serta didesain interaktif untuk kegiatan percobaan (Kresnanto, 2013). Karakteristik virtual laboratory diharapkan dapat mengatasi masalah dan hambatan yang timbul dari real laboratory, baik dari waktu, keselamatan peserta didik, serta ketersediaan alat dan bahan.

Dalam penelitian ini, peneliti menggunakan virtual laboratory yang terdapat di dalam e-module yang dikembangkan oleh Rohmah (2012) pada materi kesetimbangan kimia. E-module yang dikembangkan telah divalidasi baik dari isi 
materi, silabus dan RPP dengan pendekatan learning cycle $5 E$ oleh ahli media, serta validasi oleh pengguna, sehingga layak digunakan sebagai salah satu media pembelajaran.

Pembelajaran dengan model pembelajaran LC 5E menggunakan real laboratory dan virtual laboratory diharapkan dapat memberikan pengaruh terhadap kualitas proses pembelajaran. Kualitas proses pembelajaran merupakan kondisi dari keterlaksanaan tahapan - tahapan yang berlangsung dalam suatu proses belajar mengajar di dalam kelas maupundi laboratorium (Sulistina, 2009). Kualitas proses pembelajaran ditunjukkan dengan penilaian RTOP (Reformed Teaching Observation Protocol), lembar observasi keterlaksanaan pembelajaran serta penilaian terhadap aspek afektif dan psikomotorik peserta didik saat proses pembelajaran di kelas berlangsung (Solihin, 2010).

\section{KAJIAN LITERATUR}

\section{Tinjauan Materi Kesetimbangan Kimia}

Hasil investigasi Johnstone, dkk (1977: 169) menyimpulkan bahwa konsep sulit dan penting pada materi kesetimbangan kimia, antara lain yaitu perbedaan reaksi ke kanan dan ke kiri, interpretasi dari ketentuan panah bolak balik, pengaruh variabel pada sistem kesetimbangan termasuk prinsip Le Chatelier dan hidrolisis garam, katalis dan energi. Selain itu hasil penelitian identifikasi pemahaman konsep peserta didik yang dilakukan oleh Mukhlis (2013: 47) menyimpulkan bahwa pemahaman konseptual lebih rendah dari pemahaman algoritmik, pemahaman grafik lebih rendah dari pemahaman konseptual, serta pemahaman algoritmik peserta didik adalah yang tertinggi. Berdasarkan penelitian tersebut, dapat disimpulkan bahwa pada dasarnya pembelajaran materi kesetimbangan kimia harus ditekankan pada pemahaman makroskopik, dan simbolik secara seimbang agar pemahaman konsep peserta didik dapat tercapai secara menyeluruh.

Berdasarkan hasil investigasi kesulitan konsep dari Johnstone, dkk (1977), terdapat dua submateri yang penting dalam kesetimbangan kimia yang dapat ditunjukkan menggunakan kegiatan praktikum, yaitu reaksi irreversible, reaksi reversible dan faktor - faktor yang mempengaruhi arah pergeseran kesetimbangan. Oleh karena itu, materi kesetimbangan kimia akan lebih baik jika dibelajarkan menggunakan model pembelajaran yang tepat disertai dengan serangkaian kegiatan praktikum.

\section{Model Pembelajaran Learning Cycle 5E (LC 5E)}

Siklus belajar (learning cycle) adalah suatu model pembelajaran yang melibatkan peserta didik secara langsung pada kegiatan penelitian (investigation) secara aktif (Barman \& Kotar dalam Dasna \& Sutrisno, 2005: 69). Dalam LC peserta didik akan dapat mengembangkan pemahamannya terhadap suatu konsep dengan kegiatan mencoba (hands - on activities) sebelum diperkenalkan dengan buku atau sumber lainnya untuk memperoleh informasi.

Pada awalnya berdasarkan pengembangan teori Jean Piaget, LC memiliki 3 fase, yaitu fase pengumpulan data (gathering data/exploration), fase penemuan konsep (conceptual invention) dan fase pengembangan konsep (conceptual 
expansion) (Renner \& Abraham, 1989). Seiring dengan perkembangan proses pembelajaran, LC berkembang menjadi 4 fase, 5 fase dan 6 fase. Berdasarkan karakter materi kesetimbangan kimia yang mencakup pemahaman makroskopik, mikroskopoik dan simbolik, model pembelajaran LC 5E lebih cocok untuk digunakan karena sintaksnya lebih rinci sehingga peserta didik diharapkan dapat memperoleh keterampilan - keterampilan proses sains melalui aktifitas - aktifitas belajar yang diberikan pada fase - fase LC 5E. Menurut Bybee, dkk (2006: 1) pengembangan model pembelajaran berdasarkan BSCS, LC 5E terdiri dari, fase pendahuluan (engagement), fase eksplorasi (exploration), fase eksplanasi (explanation), fase elaborasi (elaboration) dan fase evaluasi (evaluation).

Kegiatan pada fase pendahuluan bertujuan untuk mendapatkan perhatian peserta didik, mendorong kemampuan berpikirnya, dan membantu mereka mengakses pengetahuan awal yang telah dimilikinya (Dasna \& Sutrisno, 2005). Aktifitas pada fase ini harus dapat membuat peserta didik mampu menghubungkan antara pengalaman sebelumnya dengan pengalaman saat ini, menyingkap konsep sebelumnya dan mengorganisasikan pemikiran peserta didik terhadap hasil belajar dari aktifitas yang dilakukan.

Pengalaman pada fase eksplorasi disediakan untuk peserta didik dengan aktifitas yang biasa dilakukan dalam identifikasi konsep yang dipelajari, proses dan keterampilan peserta didik, serta memudahkan perubahan konsep peserta didik (Bybee, 2006). Pada fase ini, peserta didik dapat melakukan kegiatan laboratorium untuk menolong mereka dalam menggunakan pengetahuan sebelumnya untuk menghasilkan ide baru, menggali pertanyaan dan kemungkinan yang terjadi, serta pola dan tingkah laku sebagai persiapan investigasi. Pada fase ini peserta diharapkan mengalami ketidakseimbangan kognitif (disequilibrium) (Dasna \& Sutrisno, 2005). Hal ini yang membua peserta didik mengalami modifikasi struktur kognitif berdasarkan pengalaman yang telah dilakukan sehingga terbentuk konsep baru dalam pembelajaran.

Kegiatan pada fase eksplanasi bertujuan untuk melengkapi, menyempurnakan dan mengembangkan konsep yang diperoleh peserta didik (Dasna \& Sutrisno, 2005). Fase ini memfokuskan pada perhatian peserta didik terhadap fakta yang diperoleh pada fase pendahuluan dan pengalaman saat fase eksplorasi, serta memberikan peluang untuk mendemonstrasikan pemahaman konsep, keterampilan proses atau perilaku. Selain itu, pada fase ini juga memberikan peluang pada guru untuk memperkenalkan konsep, keterampilan dan perilaku secara langsung, sehingga penjelasan guru dapat mengarahkan peserta didik terhadap pemahaman yang lebih dalam.

Kegiatan pada fase elaborasi mengarahkan peserta didik menerapkan konsep - konsep yang telah dipahami dan keterampilan yang dimiliki pada situasi baru (tetapi similiar), tujuannya untuk meningkatkan pemahaman peserta didik tentang apa yang telah mereka ketahui (Dasna \& Sutrisno, 2005). Penerapan konsep yang telah diketahui pada situasi yang baru akan membuat peserta didik dapat melakukan akomodasi melalui hubungan antarkonsep sehingga pemahaman peserta didik menjadi lebih mantap.

Kegiatan pada fase evaluasi bertujuan untuk mengetahui dua hal, yaitu pengalaman belajar yang telah diperoleh peserta didik, dan refleksi untuk 
melakukan siklus lebih lanjut, yaitu pembelajaran pada konsep berikutnya. Pada tujuan kedua, guru dapat mengajukan pertanyaan terbuka (open - ended question) yang dapat dijawab dengan menggunakan observasi, fakta/data dan penjelasan sebelumnya yang dapat diterima (Dasna \& Sutrisno, 2005). Dengan kata lain pertanyaan yang diajukan oleh guru dapat membuat peserta didik memiliki tantangan atau masalah baru yang perlu diteliti lebih lanjut.

\section{Kerja Laboratorium}

Mempelajari IPA kurang dapat berhasil bila tidak ditunjang dengan kegiatan laboratorium (Arifin, 2005), salah satunya adalah mata pelajaran kimia. Metode praktikum memiliki fungsi sebagai penunjang kegiatan proses belajar mengajar untuk menemukan prinsip tertentu atau menjelaskan tentang prinsip prinsip yang dikembangkan (Arifin, 2005), sehingga dalam pembelajaran kimia laboratorium akan menuntun peserta didik untuk melakukan praktikum berdasarkan fenomena atau fakta yang terjadi di sekitar peserta didik yang sesuai dengan materi yang akan diajarkan.

Fungsi laboratorium tidak hanya diartikan sebagai tempat untuk kegiatan belajar mengajar yang sekedar mengecek atau mencocokkan kebenaran teori yang telah diajarkan di kelas (Arifin, 2005). Namun juga memiliki fungsi untuk mengembangkan proses berfikir peserta didik dengan menemukan gejala - gejala atau fenomena yang terjadi selama kegiatan praktikum berlangsung.

Menurut Sastrawijaya (1988: 135) kerja praktek dalam kimia (kerja laboratorium) dapat dibagi dalam beberapa macam, yaitu (1) praktikum oleh peserta didik, (2) praktikum yang didemonstrasikan kepada peserta didik, (3) praktikum yang tidak ditunjukkan secara langsung, tetapi melalui alat peraga, dan (4) praktikum yang hanya diceritakan oleh guru atau buku. Oleh karena itu, berdasarkan pemaparan tersebut, peneliti hanya menggunakan 2 macam kerja laboratorium, yaitu (1) praktikum oleh peserta didik dan atau yang didemonstrasikan, yang disebut dengan laboratorium ril (real laboratory), dan (2) praktikum yang tidak ditunjukkan secara langsung atau menggunakan alat peraga, yang disebut dengan laboratorium virtual (virtual laboratory).

Istilah real laboratory digunakan untuk laboratorium sebenarnya atau laboratorium nyata, yaitu suatu laboratorium yang semua alat dan bahan yang digunakan untuk keperluan kegiatan praktikum adalah benar - benar nyata (Kresnanto, 2013). Real laboratory pada intinya merupakan suatu laboratorium nyata yang semua alat dan bahan yang akan digunakan dapat dipegang dan dilihat secara nyata dan dilakukan oleh peserta didik. Dalam hal ini real laboratory yang dimaksudkan adalah laboratorium kimia yang ada di sekolah - sekolah untuk melaksanakan kegiatan praktikum.

Sedangkan istilah virtual laboratory merupakan pembelajaran yang kegiatan praktikumnya dilakukan di laboratorium virtual yang mensimulasikan atau menirukan lingkungan dan proses real laboratory sehingga peserta didik mengamati fenomena melalui program aplikasi (software) yang dirancang khusus berupa video kegiatan praktikum dengan menggunakan bantuan komputer atau laptop (Wahyuni, 2014). Berdasarkan definisi tersebut, maka virtual laboratory dapat dikatakan sebagai media pembelajaran yang memuat proses kegiatan 
praktikum dalam pembelajaran kimia. Virtual laboratory yang peneliti gunakan dalam penelitian ini merujuk dari virtual laboratory yang terdapat di dalam $e$ module karya Rohmah (2012). Contoh tampilan virtual laboratory yang digunakan seperti pada Gambar 1 dan Gambar 2.

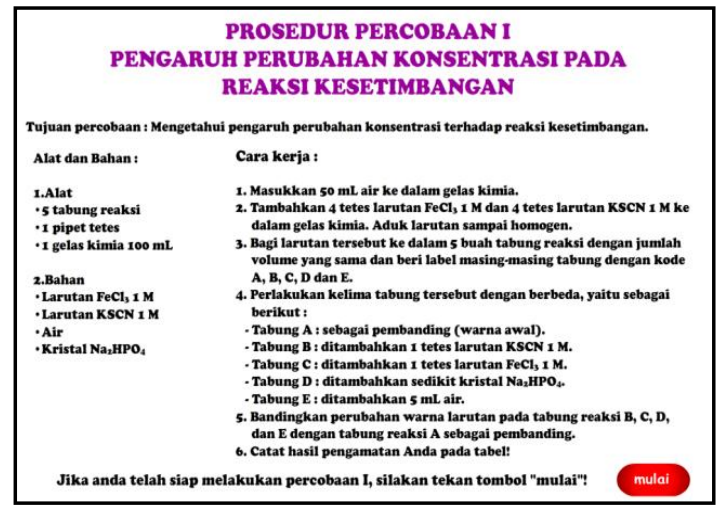

Gambar 1 : Tampilan Awal Virtual Laboratory

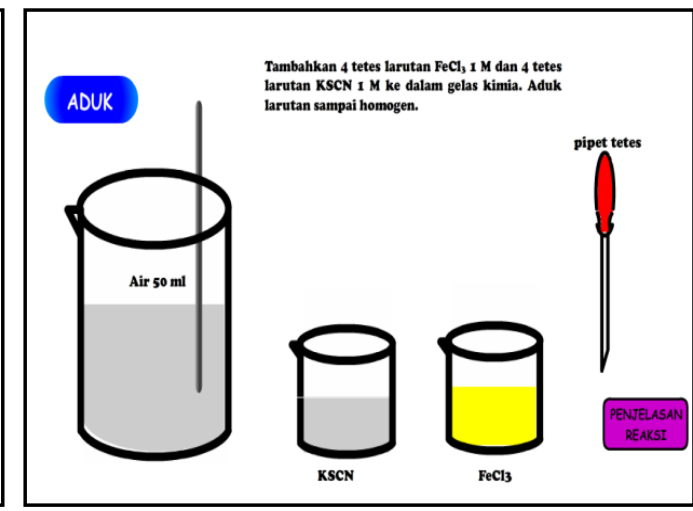

Gambar 2 : Tampilan Percobaan pada Virtual Laboratory

\section{Kualitas Proses Pembelajaran}

Menurut Phillips, dkk (2010: 2496) belajar memiliki tiga komponen, yaitu lingkungan belajar, proses belajar dan hasil belajar. Dari ketiga komponen tersebut saling berhubungan, namun yang paling diperhatikan adalah proses belajar. Selama ini proses pembelajaran banyak diarahkan kepada proses menghafal informasi yang disajikan oleh guru (Suyanti R. , 2010). Oleh karena itu, haruslah dilakukan peninjauan kembali untuk memperbaiki kualitas proses belajar mengajar. Tujuan perbaikan kualitas proses belajar ini adalah untuk membantu peserta didik agar dapat belajar secara mandiri dan kreatif sehingga peserta didik dapat memperoleh pengetahuan, keterampilan dan sikap yang dapat menunjang terbentuknya kepribadian yang mandiri.

Berdasarkan hal tersebut, penilaian proses belajar tidak hanya dinilai pada ranah kognitif, namun juga pada ranah afektif dan psikomotorik. Menurut Sulistina (2009: 9) kualitas proses pembelajaran merupakan kondisi dari keterlaksanaan tahapan - tahapan yang berlangsung dalam suatu proses belajar mengajar baik di dalam kelas maupun di laboratorium. Kualitas proses pembelajaran diukur dari lembar observasi, dokumentasi dan hasil diskusi dari Lembar Kerja Peserta Didik (LKPD) (Suryati, 2011). Sedangkan menurut Solihin (2010: 96) kualitas proses pembelajaran ditunjukkan dengan penilaian RTOP (Reformed Teaching Observation Protocol), lembar observasi keterlaksaan pembelajaran, serta penilaian terhadap aspek afektif dan psikomotorik saat proses pembelajaran di kelas berlangsung.

Berdasarkan tujuan penelitian ini, maka tingkat keberhasilan pembelajaran dan pencapaian hasil belajar peserta didik ditunjukkan dengan penilaian proses pembelajaran sebagai indikator kualitas proses pembelajaran, yaitu menggunakan penilaian RTOP (Reformed Teaching Observation Protocol), lembar observasi keterlaksanaan pembelajaran serta penilaian terhadap aspek afektif dan aspek 
psikomotorik peserta didik. Sedangkan untuk aspek kognitif diukur menggunakan penilaian pemahaman konsep peserta didik.

\section{METODE PENELITIAN}

\section{Desain Penelitian}

Desain penelitian ini berupa rancangan eksperimental semu berdasarkan perlakuan berbeda yang akan dilakukan pada subjek penelitian yaitu Static Group Comparison Design atau Non-equivalent Control Group Design (Fraenkel \& Wallen, 2009), dengan desain factorial 2x2 atau Factorialized (2x2) Version of Non-equivalent Control Group Design disajikan pada Tabel 1 berikut:

Tabel 1. Rancangan Penelitian Factorialized (2x2) Version of Non-equivalent Design

\begin{tabular}{lcc} 
Variabel Bebas & $\begin{array}{c}\text { LC 5E Real } \\
\text { Laboratory (X1) }\end{array}$ & $\begin{array}{c}\text { LC 5E Virtacl } \\
\text { Laboratory (X2) }\end{array}$ \\
\hline Kemampuan Awal Peserta Didik Tinggi (Y1) & $\mathrm{X} 1 . \mathrm{Y} 1$ & $\mathrm{X} 2 . \mathrm{Y} 1$ \\
Kemampuan Awal Peserta Didik Rendah (Y2) & $\mathrm{X} 1 . \mathrm{Y} 2$ & $\mathrm{X} 2 . \mathrm{Y} 2$ \\
\hline
\end{tabular}

\footnotetext{
Keterangan :

XI.Y1 : Pemahaman konsep peserta didik yang memiliki kemampuan awal tinggi dengan model pembelajaran LC SE menggunakan real laboratory

$\mathrm{X} 1 . \mathrm{Y} 2$ : Pemahaman konsep peserta didik yang memiliki kemampuan awal rendah dengan model pembelajaran LC SE menggunakan real laboratory

X2.Y1 : Pemahaman konsep peserta didik yang memiliki kemampuan awal tinggi dengan model pembelajaran LC SE menggunakan virfial laboratory

$\mathrm{X} 2$. Y2 : Pemahaman konsep peserta didik yang memiliki kemampuan awal rendah dengan model pembelajaran LC SE menggunakan virfual laboratory
}

Penilaian kualitas proses pembelajaran diukur melalui penilaian RTOP dan lembar observasi keterlaksanaan pembelajaran, baik pada kelas dengan model pembelajaran LC 5E menggunakan real laboratory dan virtual laboratory.

\section{Tempat dan Subjek Penelitian}

Penelitian ini dilakukan pada bulan April - Mei 2015 di SMA Negeri 2 Malang yang dilakukan selama delapan kali pertemuan menggunakan lima RPP (Rencana Pelaksanaan Pembelajaran) dengan rincian disajikan pada Tabel 2 berikut:

Tabel 2. Rincian Pertemuan pada Tiap - Tiap RPP

\begin{tabular}{cccc}
\hline Pertemuan & Alokasi Waktu & \multicolumn{2}{c}{ Tempat Pembelajaran } \\
\cline { 3 - 4 } & & Real Laboratory & Virtual Laboratory \\
\hline RPP I & 1 kali pertemuan $(2 \times 45$ menit) & Di laboratorium & Di kelas \\
RPP II & 1 kali pertemuan ( $2 \times 45$ menit) & Di kelas & Di kelas \\
RPP III & 2 kali pertemuan $(4 \times 45$ menit) & Di laboratorium & Di kelas \\
RPP IV & 1 kali pertemuan $(2 \times 45$ menit) & Di kelas & Di kelas \\
RPP V & 2 kali pertemuan $(4 \times 45$ menit) & Di kelas & Di kelas \\
Ulangan Harian & 1 kali pertemuan ( $2 \times 45$ menit) & Di kelas & Di kelas \\
\hline
\end{tabular}

Penentuan subjek penelitian dilakukan dengan teknik availability sampling atau convenience sampling, sehingga diperoleh dua kelas subjek penelitian, yaitu kelas XI MIA 4 dan XI MIA 5. Dua kelas ini dipilih sebagai subjek penelitian karena memiliki karakteristik yang relatif sama berdasarkan uji 
kesamaan dua rata - rata dari rata - rata nilai ulangan harian tiga materi sebelumnya. Pemilihan kelompok eksperimen dan kelompok pembanding dilakukan dengan undian, diperoleh hasil yaitu, kelompok eksperimen dengan model pembelajaran LC 5E menggunakan virtual laboratory adalah kelas XI MIA 5, dan kelompok pembanding dengan model pembelajaran LC 5E menggunakan real laboratory adalah kelas XI MIA 4.

\section{Pengumpulan dan Analisis Data}

Pengumpulan data dilakukan dengan menentukan instrumen penelitian yang meliputi instrumen perlakuan dan instrumen pengukuran. Instrumen perlakuan pada penelitian ini berupa perangkat pembelajaran yang terdiri dari RPP (Rencana Pelaksanaan Pembelajaran) dan bahan ajar materi kesetimbangan kimia. Semua instrumen perlakuan telah divalidasi oleh dua dosen kimia Universitas Negeri Malang dan satu guru kimia SMA Negeri 2 Malang, dengan hasil layak digunakan sebagai instrumen perlakuan.

Instrumen pengukuran pada penelitian ini berupa lembar RTOP dan lembar observasi keterlaksanaan pembelajaran. Lembar RTOP berisi identitas kelas dan guru yang diobservasi, desain pembelajaran dan implementasi, proporsi pengetahuan, prosedur pengetahuan, interaksi yang komunikatif, hubungan peserta didik dan guru, serta kritik dan saran dari observer. Sedangkan lembar observasi keterlaksanaan pembelajaran berisi lembar observasi yang disertai dengan rubrik yang sesuai dengan tahapan - tahapan pembelajaran pada RPP.

Pengumpulan data dilakukan selama delapan kali pertemuan dengan jenis data penelitian berupa data primer, yang meliputi hasil observasi menggunakan RTOP dan lembar observasi keterlaksanaan pembelajaran serta penilaian afektif dan psikomotorik. Teknik pengumpulan data menggunakan observasi afektif dan psikomotor, observasi menggunakan RTOP, dan observasi keterlaksanaan pembelajaran saat proses pembelajaran berlangsung yang dibantu oleh beberapa observer.

Analisis data kualitas proses pembelajaran dilakukan menggunakan analisis secara deskriptif, yaitu dengan menjabarkan data - data yang diperoleh dari penilaian observer menggunakan RTOP dan lembar keterlaksanaan pembelajaran serta penilaian afektif dan psikomotorik, kemudian dideskripsikan. Hal ini dilakukan agar data - data yang diperoleh dapat bermakna sehingga dapat menunjukkan keterlaksanaan pembelajaran dan kualitas proses pembelajaran yang telah terlaksana, baik pada kelompok eksperimen maupun kelompok pembanding.

\section{HASIL DAN PEMBAHASAN}

Proses pembelajaran materi kesetimbangan kimia dalam penelitian ini dilakukan pada peserta didik SMA Negeri 2 Malang kelas XI MIA 4 sebagai kelompok yang dibelajarkan menggunakan real laboratory dan kelas XI MIA 5 dibelajarkan menggunakan virtual laboratory. Kedua kelas dibelajarkan dengan jumlah pertemuan yang sama, yaitu enam kali pertemuan dengan rincian lima kali pertemuan untuk pembelajaran materi dan satu pertemuan untuk ulangan harian. Perbedaan proses pembelajaran pada kedua kelas terdapat pada pertemuan ke - I 
dan III dimana kegiatan praktikum pada kelas XI MIA 4 dilakukan di laboratorium riil (real laboratory), sedangkan pada kelas XI MIA 5 dilakukan menggunakan laboratorium virtual (virtual laboratory) dalam bentuk program $e$ module.

Hasil kualitas proses diperoleh dengan menggunakan lembar RTOP, lembar observasi keterlaksanaan pembelajaran, penilaian afektif dan psikomotor. Penilaian kualitas proses dan keterlaksanaan pembelajaran dilakukan oleh beberapa observer pada saat pembelajaran berlangsung berdasarkan aktifitas guru dan peserta didik, serta persentase keterlaksanaan tahapan - tahapan pembelajaran masing - masing kelas dalam lima kali pertemuan sesuai RPP. Berdasarkan perbedaan proses pembelajaran pada kedua kelas terdapat pada pertemuan ke - I dan III, hasil kualitas proses pembelajaran menggunakan instrumen RTOP disajikan pada Tabel 3.

Tabel 3. Penilaian Kualitas Proses Pembelajaran Menggunakan RTOP

\begin{tabular}{|c|c|c|c|c|}
\hline \multirow[t]{2}{*}{ Item yang Dinilai } & \multicolumn{2}{|c|}{$\begin{array}{c}\text { LC 5E dengan Real } \\
\text { Laboratory }\end{array}$} & \multicolumn{2}{|c|}{$\begin{array}{c}\text { LC 5E dengan } \\
\text { Virtual Laboratory }\end{array}$} \\
\hline & RPP I & RPP III & RPP I & RPP III \\
\hline Desain Pembelajaran dan Implementasi & 2,8 & 3,33 & 3,2 & 2,73 \\
\hline Proporsi Pengetahuan & 2,93 & 3,6 & 3,5 & 3,27 \\
\hline Prosedur Pengetahuan & 2,6 & 3,53 & 2,95 & 2,73 \\
\hline Interaksi yang Komunikatif & 2,6 & 3,33 & 3,25 & 3,2 \\
\hline Hubungan Peserta Didik dan Guru & 3,07 & 3,87 & 3,35 & 3,47 \\
\hline Rata-Rata & 2,8 & $\mathbf{3 , 5 3}$ & 3,25 & 3,08 \\
\hline Rata-Rata Pertemuan RPP ke-I dan ke-III & \multicolumn{2}{|c|}{$\mathbf{3 , 1 7}$} & \multicolumn{2}{|c|}{3,17} \\
\hline
\end{tabular}

Selain menggunakan lembar RTOP, kualitas proses pembelajaran dapat diketahui pula melalui penilaian keterlaksanaan pembelajaran menggunakan lembar observasi keterlaksanaan pembelajaran, penilaian afektif dan psikomotor. Penilaian lembar observasi keterlaksanaan pembelajaran didasarkan pada kesesuaian tahapan - tahapan mengajar guru dengan RPP yang telah ditentukan. Penilaian afektif terdiri dari penilaian lembar observasi sosial dan penilaian lembar observasi keterampilan diskusi. Penilaian psikomotorik terdiri dari penilaian unjuk kerja (hanya untuk kelompok yang dibelajarkan menggunakan real laboratory), portofolio dan laporan praktikum (untuk kedua kelompok). Hasil persentase keterlaksanaan pembelajaran berdasarkan observasi keterlaksanaan pembelajaran, penilaian afektif dan psikomotor pada pertemuan RPP ke - I dan III disajikan pada Tabel 4, Tabel 5, Tabel 6 dan Tabel 7.

Tabel 4. Penilaian Keterlaksanaan Pembelajaran Menggunakan Observasi Keterlaksanaan Pembelajaran

\begin{tabular}{ccccccccc}
\hline $\begin{array}{c}\text { Aspek yang } \\
\text { Dinilai }\end{array}$ & \multicolumn{3}{c}{ LC 5E dengan Real Laboratory } & \multicolumn{3}{c}{ LC 5E dengan Virtual Laboratory } \\
\cline { 2 - 9 } & $\begin{array}{c}\text { Skor } \\
\text { RPP }\end{array}$ & $\begin{array}{c}\text { Skor } \\
\text { RPP } \\
\text { I }\end{array}$ & $\begin{array}{c}\text { Rata } \\
\text { III }\end{array}$ & $\begin{array}{c}\text { Rata } \\
\text { Keterlaksa } \\
\text { naan }\end{array}$ & $\begin{array}{c}\text { Skor } \\
\text { RPP } \\
\text { I }\end{array}$ & $\begin{array}{c}\text { Skor } \\
\text { RPP } \\
\text { III }\end{array}$ & $\begin{array}{c}\text { Rata } \\
\text { Rata }\end{array}$ & $\begin{array}{c}\text { Keterlaksa } \\
\text { naan }\end{array}$ \\
\hline $\begin{array}{c}\text { Kegiatan } \\
\text { Pendahuluan }\end{array}$ & 3 & 3,33 & 3,17 & $79 \%$ & 3,67 & 3,25 & 3,46 & $87 \%$ \\
Fase Engagedment & 3,55 & 3 & 3,28 & $82 \%$ & 3,89 & 3,22 & 3,55 & $89 \%$ \\
Fase Eksplorasi & 3,33 & 3,29 & 3,31 & $83 \%$ & 3,13 & 3,33 & 3,23 & $81 \%$ \\
Fase Eksplanasi & 3,17 & 3,42 & 3,29 & $82 \%$ & 3,75 & 3,25 & 3,5 & $88 \%$ \\
Fase Elaborasi & 4 & 3,75 & 3,87 & $97 \%$ & 3,13 & 3,83 & 3,48 & $87 \%$ \\
Fase Evaluasi & 3,67 & 3,67 & 3,67 & $92 \%$ & 3,67 & 4 & 3,84 & $96 \%$ \\
Kegiatan Penutup & 3 & 3,67 & 3,34 & $84 \%$ & 3,5 & 3,5 & 3,5 & $88 \%$ \\
\hline Rata-Rata & 3,39 & 3,45 & $\mathbf{3 , 4 1}$ & $\mathbf{8 5} \%$ & 3,53 & 3,48 & $\mathbf{3 , 5}$ & $\mathbf{8 8} \%$ \\
\hline
\end{tabular}

Orbital: Jurnal Pendidikan Kimia

Volume 3, Nomor 1, Tahun 2019 
Tabel 5. Penilaian Keterlaksanaan Pembelajaran Menggunakan Penilaian Afektif

\begin{tabular}{ccc}
\hline Skala Modus Nilai Afektif & LC 5E Real Laboratory & LC 5E Virtual Laboratory \\
\cline { 2 - 3 } & Jumlah Peserta Didik & Jumlah Peserta Didik \\
\hline 5 kali (Sangat Baik) & 9 & 0 \\
3-4 kali (Baik) & 16 & 24 \\
2 kali (Cukup) & 0 & 1 \\
1 kali (Kurang) & 0 & 0 \\
Jumlah Peserta Didik & 25 & 25 \\
\hline Ketuntasan & $100 \%$ & $100 \%$ \\
\hline
\end{tabular}

Tabel 6. Perolehan Nilai Psikomotorik Peserta Didik

\begin{tabular}{cccccc}
\hline Kelompok & $\begin{array}{c}\text { Jumlah } \\
\text { Peserta Didik }\end{array}$ & Mean & $\begin{array}{c}\text { Standar } \\
\text { Deviasi }\end{array}$ & Nilai Maks & Nilai Min \\
\hline LC 5E Real Laboratory & 25 & 87,83 & 3,34 & 93,33 & 81,67 \\
LC 5E Virtual Laboratory & 25 & 84,60 & 4,48 & 90 & 75 \\
\hline
\end{tabular}

Tabel 7. Penilaian Keterlaksanaan Pembelajaran Menggunakan Penilaian Psikomotorik

\begin{tabular}{ccc}
\hline Skala Nilai Psikomotorik & LC 5E Real Laboratory & LC 5E Virtual Laboratory \\
\cline { 2 - 3 } & Jumlah Peserta Didik & Jumlah Peserta Didik \\
\hline $0-59$ (Kurang Baik) & 0 & 0 \\
$60-75$ (Cukup Baik) & 0 & 1 \\
$76-90$ (Baik) & 18 & 24 \\
$91-100$ (Sangat Baik) & 7 & 0 \\
Jumlah Peserta Didik & 25 & 25 \\
\hline Ketuntasan & $100 \%$ & $100 \%$ \\
\hline
\end{tabular}

\section{PEMBAHASAN}

Pengamatan dan penilaian kualitas proses pembelajaran pada penelitian ini dikhususkan pada pertemuan RPP ke - I dan ke - III karena pada pertemuan tersebut kedua kelompok sampel dibelajarkan menggunakan real laboratory dan virtual laboratory. Hasil analisis deskriptif berdasarkan Tabel 3, Tabel 4, Tabel 5 dan Tabel 7 menunjukkan bahwa kualitas proses pembelajaran dengan model pembelajaran LC 5E menggunakan real laboratory dan virtual laboratory pada materi kesetimbangan kimia berada pada kategori berkualitas.

Hasil penelitian berdasarkan pengamatan keterlaksanaan pembelajaran menunjukkan bahwa kedua kelompok yang dibelajarkan dengan model pembelajaran LC 5E menggunakan real laboratory dan virtual laboratory telah dilaksanakan sesuai sintaks model pembelajaran LC 5E pada RPP yang telah disusun sebelumnya. Hal ini didukung pula dengan hasil pengamatan lembar observasi RTOP yang menunjukkan bahwa pembelajaran dengan model pembelajaran LC 5E menggunakan real laboratory dan virtual laboratory mampu meningkatkan aktifitas dan keterlibatan peserta didik dalam memperoleh pengetahuan dan keterampilan. Pengamatan RTOP ditinjau dari desain pembelajaran dan implementasi proporsi pengetahuan, prosedur pengetahuan, interaksi yang komunikatif, serta hubungan peserta didik dengan guru.

Hasil penelitian berdasarkan perolehan nilai afektif dan nilai psikomotorik juga menunjukkan bahwa pembelajaran yang telah dilaksanakan mampu meningkatkan tanggung jawab, mengembangkan sikap ilmiah dan keterampilan proses belajar peserta didik. Hal ini ditunjukkan dari ketuntasan yang dicapai oleh peserta didik baik pada perolehan nilaiafektif dan nilai psikomotorik yang mencapai $100 \%$, dengan perolehan nilai rata - rata psikomotorik pada kelompok 
yang dibelajarkan menggunakan real laboratory sebesar 87,83 dan kelompok yang dibelajarkan menggunakan virtual laboratory sebesar 84,60.

Berdasarkan hasil penelitian tersebut menunjukkan bahwa pembelajaran dengan model pembelajaran LC 5E menggunakan real laboratory dan virtual laboratory memiliki kelebihan, yaitu (1) mampu meningkatkan aktifitas dan keterlibatan peserta didik dalam memperoleh pengetahuan dan keterampilan, (2) mampu meningkatkan tanggung jawab, mengembangkan sikap ilmiah dan keterampilan proses belajar peserta didik, serta (3) dapat memberikan pengalaman kepada peserta didik untuk melaksanakan kerja laboratorium menggunakan sumber - sumber laboratorium secara efektif, baik menggunakan real laboratory maupun menggunakan virtual laboratory.

Hasil penelitian ini telah sesuai dengan penelitian sebelumnya yang menyatakan bahwa model pembelajaran LC 5E berpengaruh terhadap hasil belajar peserta didik (Tuna \& Kaçar, 2013); berpengaruh positif dan dapat meningkatkan sikap terhadap sains pada pendidikan dasar (Ören \& Tezcan, 2009); meningkatkan minat dan kepercayaan diri peserta didik terhadap sains (Hokkanen, 2011); mengaktifkan proses kognitif, mengeksplorasi pengalaman, meningkatkan motivasi belajar dan membantu mengevaluasi diri peserta didik secara individu (Qarareh, 2012); membantu siswa membangun pemahaman sains dan mengembangkan kemampuan berpikir (Akar, 2005); serta meningkatkan kemampuan memberikan alasan dan membantu untuk mengeliminasi miskonsepsi peserta didik (Lawson, 2001).

Pada pertemuan RPP ke - I, peserta didik baik pada kelompok yang dibelajarkan menggunakan real laboratory maupun yang menggunakan virtual laboratory diberikan demonstrasi yang sama, yaitu berupa pemanasan kristal $\mathrm{CuSO}_{4}$ (fase engagement), kertas yang dibakar, minuman berkarbonasi yang dikocok dan proses perebusan air pada wadah terbuka dan tertutup (fase exploration), serta reaksi irreversible yang terjadi dari endapan $\mathrm{PbSO}_{4}$ yang direaksikan dengan larutan $K I$, kemudian hasil endapan direaksikan kembali dengan larutan $\mathrm{Na}_{2} \mathrm{SO}_{4}$ (fase elaboration). Perbedaannya adalah pada kelompok yang dibelajarkan menggunakan virtual laboratory demonstrasi disampaikan dalam bentuk tayangan video yang selama pembelajaran diulang selama dua sampai tiga kali penayangan. Demonstrasi ini dipilih karena keterbatasan waktu penelitian dan menyesuaikan pertemuan antara kelompok yang dibelajarkan menggunakan real laboratory dan virtual laboratory.

Pada pertemuan RPP ke - III, peserta didik baik pada kelompok yang dibelajarkan menggunakan real laboratory maupun yang menggunakan virtual laboratory menggunakan materi praktikum yang sama, yaitu pengaruh perubahan konsentrasi dan volume terhadap pergeseran arah kesetimbangan menggunakan perubahan warna ion kompleks $[\mathrm{FeSCN}]^{2+}$ dari campuran larutan $\mathrm{FeCl}_{3}$ dengan larutan $K S C N$, serta pengaruh perubahan tekanan terhadap pergeseran arah kesetimbangan menggunakan reaksi kesetimbangan gas $\mathrm{NO}_{2}$ menjadi pas $\mathrm{N}_{2} \mathrm{O}_{4}$. Perbedaan percobaan hanya pada percobaan pengaruh perubahan suhu terhadap pergeseran arah kesetimbangan, dimana kelompok real laboratory menggunakan 
perubahan warna ion kompleks yang terjadi pada campuran kristal $\mathrm{NaCl}$ dengan larutan $\mathrm{CuSO}_{4}$, sedangkan kelompok virtual laboratory menggunakan perubahan warna air brom. Hal ini terjadi karena keterbatasan waktu, peralatan dan bahan kimia yang digunakan untuk membuat air brom, serta mempertimbangkan keamanan dan keselamatan kerja bagi peserta didik jika menggunakan air brom.

Perbedaan materi praktikum yang dilakukan pada kedua kelompok ini pada kenyataannya tidak mempengaruhi kualitas proses pembelajaran. Hal ini terjadi karena kerja sama antarpeserta didik dalam setiap kelompok sangat baik, sehingga dapat meminimalisir terjadinya perbedaan kualitas proses pembelajaran. Selain itu, selama proses pembelajaran berlangsung, baik di dalam kelas maupun di dalam laboratorium, semua peserta didik dapat mengikuti proses pembelajaran sesuai sintaks dan fase - fase dalam model pembelajaran LC 5E. Hal ini terjadi karena sampel peserta didik sudah terbiasa menggunakan pembelajaran dengan prinsipkonstruktivistik, salah satunya 5E, sehingga semua peserta didik aktif merespon segala bentuk permasalahan dan fenomena yang disajikan selama pembelajaran, terutama saat proses praktikum. Oleh karena itu, proses pembelajaran dapat terlaksana dengan baik dan menghasilkan kualitas proses pembelajaran yang baik pula.

\section{KESIMPULAN DAN SARAN}

Berdasarkan hasil penelitian dan pembahasan yang telah diuraikan sebelumnya, dapat ditarik kesimpulan bahwa kualitas proses pembelajaran dengan model pembelajaran LC 5E baik menggunakan real laboratory maupun menggunakan virtual laboratory pada materi kesetimbangan kimia berada pada kategori berkualitas baik, yang ditunjukkan dengan rata - rata skor hasil observasi menggunakan lembar RTOP, lembar keterlaksanaan pembelajaran, perolehan nilai afektif dan nilai psikomotorik yang baik dan tuntas. Beberapa saran yang dapat diberikan kepada pihak - pihak yang berkepentingan adalah (1) bagi peserta didik : dapat memilih media pembelajaran yang sesuai dengan gaya belajarnya, baik menggunakan real laboratory maupun virtual laboratory, untuk memperbaiki hasil belajarnya; (2) bagi guru : virtual laboratory dapat digunakan sebagai pembekalan sebelum sesi real laboratory dilaksanakan sehingga sesi real laboratory akan dapat berjalan dengan lebih efektif dan efisien, serta virtual laboratory dapat dijadikan sebagai alternatif pengganti real laboratory karena kendala keterbatasan waktu, sarana dan prasarana di sekolah yang kurang memadai; serta (3) bagi peneliti lain: frekuensi pertemuan untuk melakukan kegiatan praktikum baik real laboratory maupun virtual laboratory dapat diperbanyak agar penyampaian materi kesetimbangan kimia dapat disampaikan secara menyeluruh dan kualitas pembelajaran semakin tinggi.

\section{DAFTAR PUSTAKA}

Akar, E. (2005). Efectivenes of 5E Learning Cycle Model on Student's Undersatnding of Acid Base Concept. Thesis: Middle East Technical University.

Arifin, M. (2005). Strategi Belajar Mengajar Kimia. Malang: UM Press. 
Bybee, R. W. (2006). The BSCS 5E Instructional Model: Origins, Effectiveness and Aplications. Executive Summary: Biological Science Curriculum Study (BSCS). Colorado: Mark Dabling Boulevard.

Dahar, R. W. (2011). Teori - Teori Belajar dan Pembelajaran. Jakarta: Penerbit Erlangga.

Dasna, I. W., \& Sutrisno. (2005). Model - Model Pembelajaran Konstruktivistik dalam Pengajaran Sains/Kimia. Malang: Jurusan Kimia, Fakultas MIPA, Universitas Negeri Malang.

Fraenkel, J. R., \& Wallen, N. E. (2009). How to Design and Evaluate Research in Education : Seventh Edition. USA: McGraw - Hill Higher Education.

Hokkanen, S. L. (2011). Improving Student Achievement, Interest and Confidence in Science Through the Implementation of The 5E Learning Cycle in The Middle Grades of An Urban School. Thesis: Montana State University.

Iskandar, S. M. (2011). Pendekatan Pembelajaran Sains Berbasis Konstruktivis. Malang: Universitas Negeri Malang.

Johnstone, A. H., MacDonald, J. J., \& Webb, G. (1977). Chemical Equilibrium and Its Conceptual Difficulties. Education on Chemistry, 169 - 171.

Kirna, I. M. (2010). Pengaruh Penggunaan Hypermedia dalam Pembelajaran Menggunakan Strategi Siklus Belajar Terhadap Pemahaman dan Aplikasi Konsep Kimia pada Siswa SMP dengan Dua Gaya Belajar Berbeda. Disertasi: Universitas Negeri Malang.

Kresnanto, M. (2013). Keefektifan Virtual Laboratory dan Real Laboratory dalam Pembelajaran Kimia dengan Pendekatan Inkuiri Terbimbing terhadap Hasil Belajar Siswa SMK dengan Gaya Belajar Visual dan Kinestetik. Tesis: Universitas Negeri Malang.

Lawson, A. E. (2001). Using the Learning Cycle to Teach Biology Concept and Reasoning Pattern. Journal of Biological Education 35 , 165 - 169.

Mukhlis, M. M. (2013). Identifikasi Pemahaman Konseptual, Algoritmik, Grafik dan Gambaran Mikroskopik Siswa Kelas XI IPA di SMA Negeri 2 Malang pada Materi Kesetimbangan Kimia. Skripsi: Universitas Negeri Malang.

Ören, F. S., \& Tezcan, R. (2009). The Effectiveness of The Learning Cycle Approach on Learners Attitude Toward Science in Seventh Grade Science Classes of Elementary School. Elementary Education Online, 8 (1) , 103 118.

Phillips, R., McNaught, C., \& Kennedy, G. (2010). Toward A Generalized Conceptual Framework for Learning : The Learning Environment, Learning Processes and Learning Outcomes (LEPO) Framework. The 22nd Annual World Conference on Education Multimedia, Hypermedia and Telecomunication, ED-MEDIA, (pp. 2495 - 250).

Orbital: Jurnal Pendidikan Kimia 
Qarareh, A. O. (2012). The Effect of Using The Learning Cycle Method in Teaching Science on The Educational Achievement of The Sixth Grades. International Journal Educational Science, 4 (2), 123 - 132.

Renner, J. W., \& Abraham, M. R. (1989). The Sequence of Learning Cycle Activities in High School Chemistry. Journal of Research in Science Teaching, 23 (2), $121-143$.

Rohmah, M. (2012). Pengembangan e-module dengan Model Pembelajaran Learning Cycle 5E pada Pokok Bahasan Kesetimbangan Kimia untuk SMA Kelas XI IPA Semester Ganjil. Skripsi: Universitas Negeri Malang.

Sastrawijaya, T. (198). Proses Belajar Mengajar Kimia. Jakarta: P2LPTK, Departemen Pendidikan dan Kebudayaan Direktorat Jenderal Pendidikan Tinggi.

Setiawan, N. C. (2011). Pengaruh Model Pembelajaran dan Kemampuan Awal terhadap Hasil Belajar dan Kemampuan Berpikir Tingkat Tinggi Siswa Kelas XI IPA SMA Negeri 1 Turen pada Materi Kesetimbangan Kimia. Tesis: Universitas Negeri Malang.

Solihin, I. (2010). Keefektifan Model Pembelajaran Inkuiri Terbuka dan Learning Cycle dalam Meningkatkan Kualitas Proses dan Hasil Belajar Kimia Siswa Kelas X SMA Negeri 3 Bontang. Tesis: Universitas Negeri Malang.

Sulistina, O. (2009). Keefektifan Penggunaan Metoda Pembelajaran Inkuiri Terbuka dan Inkuiri Terbimbing dalam Meningkatkan Kualitas Proses Pembelajaran dan Hasil Belajar Siswa Kelas X SMA Laboratorium Malang. Tesis: Universitas Negeri Malang.

Suryati. (2011). Pengaruh Model Pembelajaran Learning Cycle Dipadu dengan Diagram Alir terhadap Kualitas Proses, Hasil Belajar dan Kemampuan Metakognitif Kimia Siswa Kelas XI SMA Negeri 2 Malang. Tesis: Universitas Negeri Malang.

Suyanti, R. (2010). Strategi Pembelajaran Kimia. Yogyakarta: Graha Ilmu.

Suyanti, R. D. (2010). Strategi Pembelajaran Kimia. Yogyakarta: Graha Ilmu.

Suyono, \& Haryanto. (2014). Belajar dan Pembelajaran : Teori dan Konsep Dasar. Bandung: PT. Remaja Rosdakarya.

Tuna, A., \& Kaçar, A. (2013). The Effect of 5E Learning Cycle Model in Teaching Trigonometry on Student's Academic Achievement and Performance of Their Knowledge. International Journal on New Trends in Education and Their Implication, 4 (1), 73 - 87.

Wahyuni, T. S. (2014). Pengaruh Pembelajaran Inkuiri Terbimbing Menggunakan Real-Lab dan Virtual-Lab terhadap Pemahaman Representasi Kimia dan Motivasi Siswa pada Materi Kelarutan dan Hasil Kali Kelarutan. Tesis: Universitas Negeri Malang. 